\title{
INCOME, CHARITABLE GIVING, AND PERCEPTION BIAS
}

\section{Kun Su, Rui Wan*}

\begin{abstract}
This paper analyses income and charitable giving from the perspective of perception bias. We show that perception bias affects charitable giving through its effects on warm glow, while inequality aversion counteracts these effects. Donors' perception bias regarding a recipient's situation does not necessarily decrease their charitable giving. Specifically, perception bias regarding the recipients' effort and life shock decreases donors' charitable giving. Perception bias regarding the recipients' ability decreases donors' giving to charities designed to help low-ability recipients but increases their giving to charities designed to help high-ability recipients. We also show that perception bias increases with donors' income. Fundraising professionals shall allocate more efforts to those who do not care about inequality that much when correcting the donors' perception bias; focus their efforts on correcting the donors' perception bias, especially for rich donors, when raising money for charities with low-ability recipients; but increase donors' perception bias regarding the recipients' ability when raising money for charities with high-ability recipients.
\end{abstract}

Keywords: charitable giving, inequality aversion, perception bias, warm glow JEL Classification: D64, D63

\section{Introduction}

Charitable giving comes from various sources, such as bequests, corporations, foundations, and individuals. Individual donors are the single largest source of overall charitable donations in many countries and represented over $70 \%$ of total charitable donations over the past 40 years in the United States as shown in Figure $1 .{ }^{1}$ However, despite per capita income having increased considerably over time, the percentage of income donated to charity has been relatively stable. Figure 2 shows that the percentage remains around $2 \%$, while disposable personal income (DPI) in the United States has steadily risen from \$5,145 billion in 1974 to $\$ 12,986$ billion in $2014 .^{2}$ Interestingly, this phenomenon holds across many countries. ${ }^{3}$

* Kun Su, School of Management, Northwestern Polytechnical University (sukun@nwpu.edu.cn); Rui Wan, School of Economics, Nanjing University (wanrui@nju.edu.cn) - corresponding author. The authors are grateful to Jingping Li for constructive suggestions. We are indebted to M. Scott Taylor and Subhasish Dugar for valuable comments. We thank the editor and two anonymous referees for great suggestions. This study was supported by the National Natural Science Foundation of China Grant No. 71402141 and No. 71773088, the China Postdoctoral Science Foundation (No. 2015M582705, No. 2016T90943, No. 2016M600389), and the Fundamental Research Funds for the Central Universities in Northwestern Polytechnical University (No. 3102017jc19005). All errors are our own.

1 Data source: Giving USA 2015. Inflation adjustment is calculated by using the Consumer Price Index, and the base year is 2014 .

2 Data source: Giving USA 2015.

3 Similar trend has been observed in the UK (Bennett, 2012; Bashir et al., 2013), and Ireland (Donoghue and Ruddle, 2000; Carroll et al., 2005). 
The relatively flat relationship between income and the percentage donated to charity has motivated various studies. Income elasticities of charitable giving are estimated to range from 0.40 to 0.87 in the United States (Auten et al., 2002) and from 0.19 to 0.32 in the Netherlands (Bekkers, 2004), but evidence from experimental studies is mixed (Andreoni and Vesterlund, 2001; Buckley and Croson, 2006; Erkal et al., 2011). ${ }^{4}$ The relationship between income and the percentage donated to charity has attracted the attention of many scholars, but there is no agreement on the mechanism behind donors' giving decisions.

The explanation for charitable giving generally falls into three broad categories: (1) the pure altruism, where an individual selflessly cares for others (Becker, 1974); (2) the impure altruism that combines pure altruism and the "warm glow" representing the donor's pleasure from the act of giving (Andreoni, 1995, 1989, 1990); ${ }^{5}$ and (3) the social preference case, which most often includes inequity aversion (Bolton and Ockenfels, 2000; Fehr and Schmidt, 1999). Andreoni (2006) argues that warm glow has substantial influences on a donor's behaviour. Mayo and Tinsley (2009) suggest that considering the nature and determinants of the "warm glow" is critical to understanding the fundamental drivers of giving. Additionally, psychologists and sociologists have long established that donors have distinct perceptions of the same recipient and thus experience diverse types of warm glow from charitable giving. However, these findings have been largely overlooked in the study of philanthropy. Based on the "self-serving attribution bias," individuals tend to attribute their successes to personal factors and their failures to situational factors beyond their control (Miller and Ross, 1975; Mullen and Riordan, 1988). When assessing others, however, individuals tend to over-value personality-based explanations and undervalue situational explanations, according to the "fundamental attribution error" (Ross, 1977). Mayo and Tinsley (2009) demonstrate that these two types of psychological perception biases are critical in explaining the stable pattern of charitable giving as a share of national income.

This paper extends the analysis in Mayo and Tinsley (2009) and incorporates impure altruism, inequality aversion, and perception bias. ${ }^{6}$ Individual income is determined by one's intrinsic ability, working effort, and random life shock. Donors care not only about their own income consumption but also the consumption of people who are less well off than they are. Donors enjoy an additional benefit from charitable giving in the form of warm glow that further depends on the donors' perception of the recipients' situation regarding their ability, working effort, and life shock. We show that perception bias affects charitable

$4 \quad$ Andreoni (2006) finds a U-shaped relationship between household income and the percentage given to charity based on data from the United States.

5 Distinguishing warm glow from pure altruism has implications for the so-called crowding out hypothesis, which argues that private charitable giving may be crowded out by public spending (Tonin and Vlassopoulos, 2014). This is not the focus of this paper. Refer to Andreoni (2006) and Vesterlund (2006) for detailed surveys of this hypothesis.

6 Perception bias in this paper refers to two types of psychological perception biases: the "selfserving attribution bias" and the "fundamental attribution error" explained above. Biased perception of income distribution is not the focus of this paper. Cruces et al. (2013) discuss the mechanism of this type of perception bias and its impact on redistributive policies. 
giving through its effects on warm glow, while inequality aversion counteracts these effects. However, perception bias does not necessarily decrease charitable giving. Specifically, donors' perception bias regarding the recipients' effort and life shock decreases their charitable giving. Donors' perception bias regarding the recipients' ability decreases their giving to charities designed to help low-ability recipients but increases their giving to charities designed to help high-ability recipients. Additionally, such a bias increases with donors' income.

This paper contributes to the literature in the following aspects. First, we incorporate ability as another factor that affects the donor's warm glow. This is consistent with the existence of various types of charity. We observe in reality charitable giving designed to help individuals with less intrinsic ability as well as private funds sponsoring excellent students. Without the consideration of the recipient's ability, Mayo and Tinsley (2009) show that perception bias will systematically reduce warm glow and hence the charitable giving of rich donors. However, we argue that perception bias does not necessarily lower wealthy people's charitable giving when taking into account the donor's perception on the recipient's ability. More importantly, this setting allows us to provide insightful suggestions for fundraising professionals as stated below.

Second, individual's work effort is endogenously determined in our paper and we consider the cost of working hard. We adopt a function that has the property of CRRA (constant relative risk aversion) to include the cost of working hard. We further specify income as a CobbDouglas function of individual's ability and effort instead of a simple linear function of effort as in Mayo and Tinsley (2009) that assume a uniform distribution of effort in their simulation. Such a general setting makes our results even more reasonable and robust.

Third, we include both impure altruism and inequality aversion in our analysis. An individual enjoys the acting of charitable giving in the form of warm glow, and cares about the consumption of others who are less well off. This setting allows us to identify how the donor's attitude towards inequality affects his charitable giving with the presence of perception bias. We find that if the donor has a strong inequality aversion, the effect of perception bias on charitable giving is then relatively small, and vice versa. ${ }^{7}$ That is to say, perception bias affects charitable giving through its effects on warm glow, while inequality aversion counteracts these effects of perception bias.

Finally, our results suggest a set of strategies for charitable organizations. Our analysis indicates distinguishing charity types based on their purposes is also critical for fundraising professionals. Specifically, fundraising professionals shall focus their efforts on correcting the donors' perception bias, especially for rich donors, when raising money for charities with low-ability recipients, but they shall increase donors' perception bias regarding the recipients' ability when raising money for charities with high-ability recipients. Additionally, the donor's attitude towards inequality counteracts the effects of perception bias. Thus, understanding the level of the donor's inequality aversion helps fundraising professionals to allocate their effort efficiently. For example, they shall focus

$7 \quad$ We thank the anonymous referee for pointing this out. 
their efforts on correcting the donors' perception bias, especially for those who do not care inequality that much, when raising money for charities with low-ability recipients.

The remainder of the paper is organized as follows. Section 2 sets up the theoretical model of charitable giving that incorporates both impure altruism and inequality aversion. We first analyse the case without perception bias, and then add perception bias to explore its effect on charitable giving. Simulation in Section 3 sheds light on perception bias and individual income. Conclusion remarks are provided in Section 4. Brief description of the Mayo and Tinsley (2009) model is provided in the Appendix.

\section{Model of Charitable Giving}

\subsection{Model set up}

Based on the literature, we incorporate both inequality aversion and impure altruism into our model. An individual benefits from his own consumption, cares about the consumption of others who are less well off, and enjoys the act of charitable giving in the form of warm glow. Individual $k$ 's income depends on his intrinsic ability $a_{k}$, effort exerted in the market $e_{k}$, and random life shock $\varepsilon_{k}$ as expressed below:

$$
I_{k}=I\left(a_{k}, e_{k}\right)+\varepsilon_{k} \text {, with } I_{a}, I_{e}>0, I_{a a}, I_{e e}<0 \text {, and } I_{a e}>0 .
$$

We extend Mayo and Tinsley (2009) and define warm glow as a function of the donor's perception of the recipient's ability, effort, and life shock, besides the level of charitable giving. The utility function for donor $i$ is specified as:

$$
\begin{aligned}
& U_{i}=f\left(I_{i}-c_{i}\right)+h\left(I_{i}-c_{i}-\left(I_{j}+c_{i}\right)\right)+g\left(c_{i}, a_{j}^{*}, e_{j}^{*}, \varepsilon_{j}^{*}\right)-l\left(e_{i}\right), \\
& \text { with } i \neq j, f^{\prime}, g_{c_{i}}, g_{e_{j}^{*}}>0, h^{\prime}, g_{\varepsilon_{j}^{*}}<0, \\
& \text { and } f^{\prime \prime}, h^{\prime \prime}, g_{c_{i} c_{i}}, g_{a_{j}^{*} a_{j}^{*}}, g_{e_{j}^{*} e_{j}^{*}}, g_{\varepsilon_{j}^{*} \varepsilon_{j}^{*}}, g_{c_{i} \varepsilon_{j}^{*}}<0, g_{c_{i} e_{j}^{*}}>0,
\end{aligned}
$$

Where $c_{i}$ is the charitable giving from individual $i$ to an individual (or a set of individuals) $j$ (presumed to be less well off than individual $i$ ), while $a_{j}^{*}, e_{j}{ }_{j}$, and $\varepsilon_{j}^{*}$ represent individual $i$ 's perception of individual $j$ 's ability, effort, and life shock, respectively. Function $f$ measures individual $i$ 's benefit from his own consumption, function $h$ captures his concern for income inequality, function $g$ denotes his warm glow from charitable giving, and $l$ is cost of working effort.

Intuitively, the donor's warm glow increases with the amount of charitable giving $\left(g_{c i}>0\right)$, while it increases with his perception of the recipient's effort $\left(g_{\varepsilon_{j}^{*}}>0\right)$, and it decreases with his perception of the recipient's life shock $\left(g_{\varepsilon_{j}^{*}}<0\right)$. The sign of $g_{a_{j}^{*}}$ varies across donors and depends on the type of charity: some donors feel more sympathy for individuals with less intrinsic ability and thus enjoy more pleasure from giving to them, while the existence of private funds sponsoring excellent students suggests that certain donors prefer to support high-ability individuals.

We treat an individual's decision making as a two-step process. Individual $k$ first chooses the optimal effort $e_{k}$ to maximize his income but also takes into account the cost 
of working hard. Given the income distribution, the individual then decides on the optimal charitable giving to maximize his utility. Our theoretical analysis explores income and charitable giving for the second stage, and we examine an individual's choice of working effort for the first stage in a simulation.

\subsection{Income and charitable giving}

Given the income distribution, individual $i$ chooses the charitable giving $\mathrm{c}_{i}$ to maximize his utility $U_{i}$, and the first-order condition $\delta U_{i} / \delta c_{i}=0$ generates:

$$
-f^{\prime}\left(I_{i}-c_{i}\right)-2 h^{\prime}\left(I_{i}-c_{i}-\left(I_{j}+c_{i}\right)\right)+g_{c_{i}}\left(c_{i}, a_{j}^{*}, e_{j}^{*}, \varepsilon_{j}^{*}\right)=0 .
$$

Total differentiation of Equation 3 leads to the following:

$$
-f^{\prime \prime}\left(d I_{i}-d c_{i}\right)-2 h^{\prime \prime}\left(d I_{i}-d c_{i}-\left(d I_{j}+d c_{i}\right)\right)+g_{c_{i} c_{i}} d c_{i}+g_{c_{i} a_{j}^{*}} d a_{j}^{*}+g_{c_{i} e_{j}^{*}} d e_{j}^{*}+g_{c_{i} \varepsilon_{j}^{*}} d \varepsilon_{j}^{*}=0
$$

Where $d I_{k}=I_{a_{k}} d a_{k}+I_{e_{k}} d e_{k}+d \varepsilon_{k}$ based on Equation 1, with $k=i, j$. Rearranging Equation 4 results in:

$$
\begin{aligned}
\frac{d c_{i}}{d I_{i}}= & \frac{f^{\prime \prime}+2 h^{\prime \prime}}{f^{\prime \prime}+4 h^{\prime \prime}+g_{c_{i} c_{i}}} \\
& -\frac{1}{f^{\prime \prime}+4 h^{\prime \prime}+g_{c_{i} c_{i}}}\left(2 h^{\prime \prime} \frac{d I_{j}}{d I_{i}}+g_{c_{i} a_{j}^{*}} \frac{d a_{j}^{*}}{d I_{i}}+g_{c_{i} e_{j}^{*}} \frac{d e_{j}^{*}}{d I_{i}}+g_{c_{i} \varepsilon_{j}^{*}} \frac{d \varepsilon_{j}^{*}}{d I_{i}}\right) .
\end{aligned}
$$

To better understand the role of perception bias, we first analyse the relationship between income and charitable giving by allowing donors to have accurate perception of the recipient's situation. We then proceed to the case with perception bias.

\subsubsection{No perception bias}

If the donor's perception reflects the recipient's real situation exactly, we then have $a_{j}{ }^{*}=a_{j}, e_{j}{ }^{*}=e_{j}$, and $\varepsilon_{j}{ }^{*}=\varepsilon_{j}$. Recall that an individual can choose neither his intrinsic ability nor random life shocks that occur, and we assume individual income is pre-determined before charitable giving occurs. That is to say, $d a_{j}=0, d e_{j}=0$, and $d \varepsilon_{j}=0$, which implies $d I_{j}=0$. Without perception bias, Equation 5 then becomes:

$$
0<\frac{d c_{i}}{d I_{i}}=\frac{f^{\prime \prime}+2 h^{\prime \prime}}{f^{\prime \prime}+4 h^{\prime \prime}+g_{c_{i} c_{i}}}<1,
$$

given $f^{\prime \prime}, h^{\prime \prime}, g_{c_{i} c_{i}}<0$. This result is summarized in the following proposition.

Proposition 1. Without perception bias, charitable giving increases with the donor's income but by a smaller amount. 
Proposition 1 is in line with many studies that find a positive relationship between income and charitable giving (Bekkers and Wiepking, 2007; James and Sharpe, 2007; Wiepking, 2007). Individuals who have more money generally give more money away. Whether the percentage of income given to charity increases with income depends on whether the marginal increase in charitable giving $\left(d c_{i} / d I_{i}\right)$ exceeds the current share of income given to charity $\left(c_{i} / I_{i}\right)$. Specifically, $d\left(c_{i} / I_{i}\right) / d I_{i}>0$ if $\left(f^{\prime \prime}+2 h^{\prime \prime}\right) /\left(f^{\prime \prime}+4 h^{\prime \prime}+g_{c_{i} c_{i}}\right)>c_{i} / I_{i}$, and vice versa. ${ }^{8}$ Recall that our model incorporates inequality aversion through function $h$ and incorporates impure altruism through the warm glow function $g$. Further examination of Equation 6 suggests that Proposition 1 holds even if we only adopt either inequality aversion or impure altruism.

To understand the effect of inequality aversion we further differentiate Equation 6 with respective to $h^{\prime \prime}$ and obtain the following:

$$
d\left(\frac{d c_{i}}{d I_{i}}\right) / d h^{\prime \prime}=\frac{2\left(g_{c_{i} c_{i}}-f^{\prime \prime}\right)}{\left(f^{\prime \prime}+4 h^{\prime \prime}+g_{c_{i} c_{i}}\right)^{2}}\left\{\begin{array}{l}
>0 \text { if } f^{\prime \prime}<g_{c_{i} c_{i}} . \\
\leq 0 \text { otherwise }
\end{array}\right.
$$

Results expressed by Equation 7 indicate that the effect of inequality aversion on the relationship between income and charitable giving depends on the concavity of the consumption function $f$ and the warm glow function $g$. For donors with weak inequality aversion (smaller $\left|h^{\prime \prime}\right|$ ), the increase in the donor's charitable giving associated with rising income will become larger $\frac{d c_{i}}{d I_{i}}$ (increases) if marginal utility from consumption rises slower than the marginal utility from warm glow $\left(f^{\prime \prime}<g_{c_{i} c_{i}}\right)$, and vice versa. Therefore, even without perception bias, inequality aversion and impure altruism intertwined with each other on the relationship between income and charitable giving. Below we proceed to the case with perception bias.

\subsubsection{Perception bias}

In the presence of perception bias, $a_{j}^{*} \neq a_{j}, e_{j}^{*} \neq e_{j}$, and $\varepsilon_{j}^{*} \neq \varepsilon_{j}$, Equation 5 becomes

$$
\frac{d c_{i}}{d I_{i}}=\frac{f^{\prime \prime}+2 h^{\prime \prime}}{f^{\prime \prime}+4 h^{\prime \prime}+g_{c_{i} c_{i}}}-\frac{1}{f^{\prime \prime}+4 h^{\prime \prime}+g_{c_{i} c_{i}}}\left(g_{c_{i} a_{j}^{*}} \frac{d a_{j}^{*}}{d I_{i}}+g_{c_{i} e_{j}^{*}} \frac{d e_{j}^{*}}{d I_{i}}+g_{c_{i} \varepsilon_{j}^{*}} \frac{d \varepsilon_{j}^{*}}{d I_{i}}\right) \text {. }
$$

Comparing Equation 8 with 6 reveals that the effects of perception bias regarding charitable giving depends critically on how the donor's marginal warm glow changes with his perception of the recipient's situation $\left(g_{c_{i} a_{j}}, g_{c_{i} e_{j}}, g_{c_{i} \varepsilon_{j}}\right)$, and how the donor's perception bias changes with his income $\left(d a_{j}^{*} / d I_{i}, d e_{j}^{*} / d I_{i}, d \varepsilon_{j}{ }^{*} / d I_{i}\right)$. Intuitively, the donor's marginal warm

8 Mathematically, $d\left(c_{i} / I_{i}\right) / d I_{i}=\frac{1}{I_{i}}\left(\frac{d c_{i}}{d I_{i}}-\frac{c_{i}}{I_{i}}\right)$. 
glow generally increases with his perception of the recipient's effort $\left(g_{c_{i} e_{j}}>0\right)$ and decreases with his perception of the recipient's life shock $\left(g_{c_{i} \varepsilon_{j}}<0\right)$ (Mayo and Tinsley, 2009). We do not assign $g_{c_{i} a_{j}}$ for the utility function because $g_{c_{i} a_{j}}<0$ for donors who feel more sympathy for low-ability recipients, and $g_{c_{i} a_{j}}>0$ for donors who prefer to support talented individuals.

Donors' attitude towards inequality, on the other hand, counteracts the above effects of perception bias, expressed by the term $-\frac{1}{f^{\prime \prime}+4 h^{n}+g_{c_{i} c_{i}}}$. For donors' with strong inequality aversion (large $\left.\left|h^{\prime \prime}\right|\right)$, the effects of perception bias on their charitable giving are relatively smaller keeping other things constant. Therefore, understanding the donor's attitude towards inequality is critical for fundraising professionals to allocate their effort efficiently. For example, when correcting the donors' perception bias, they shall focus their efforts especially on those who do not care inequality that much.

The next question is how the donor's perception bias changes with income. As mentioned, individuals tend to attribute their successes to personal factors and their failures to situational factors beyond their control (the "self-serving attribution bias"). But when assessing other people, individuals tend to overvalue personality-based explanations and undervalue situational explanations (the "fundamental attribution error"). Therefore, how the donor's perception bias changes with his own income relies on the differences between the donor's and the recipient's likelihood of being born with a high ability, working hard in the market, or being shocked by good luck. Due to the lack of real data, we use a simulation to illustrate such a relationship.

\section{Simulation}

The theoretical analysis mainly focussed on the second stage of decision making where the individual chooses charitable giving to maximize his utility. We now turn to the first stage where individual $k$ chooses the optimal effort $e_{k}$ to maximize his income $I_{k}$ but also takes into account the cost of working hard.

\subsection{Simulation specification}

Without loss of generality, we assume an individual's objective for the first step has the property of CRRA (constant relative risk aversion) as shown below:

$$
\begin{gathered}
\Omega_{k}=\left\{\begin{array}{l}
\frac{I_{k}^{1-\xi}}{1-\xi}-e_{k}^{\gamma}, \text { for } \xi>0 \text { and } \xi \neq 1, \gamma>1, \\
\ln I_{k}-e_{k}^{\gamma}, \text { for } \xi=1, \gamma>1 .
\end{array}\right. \\
I_{k}=\left(a_{k}\right)^{\alpha}\left(e_{k}\right)^{\beta}+\varepsilon_{k}, \text { with } \alpha, \beta>0,
\end{gathered}
$$

where $a_{k}$ represents individual $k$ 's intrinsic ability and $\varepsilon_{k}$ is random life shock. Random life shock can occur either before the individual makes his effort decision (such as receiving an inheritance before being born) or after (such as economic crises after working hard 
in a company). If the life shock $\varepsilon_{k}$ occurs before individual $k$ makes effort $e_{k}$, then the optimal effort level satisfies the following first-order condition

$$
\left(\left(a_{k}\right)^{\alpha}\left(e_{k}\right)^{\beta}+\varepsilon_{k}\right)^{-\xi}=\frac{\gamma}{\left(a_{k}\right)^{\alpha} \beta}\left(e_{k}\right)^{\gamma-\beta} .
$$

If the life shock $\varepsilon_{k}$ occurs after individual $k$ decides his effort, then optimal $e_{k}$ maximizes the expected objective function $\Omega_{k}$ given the distribution of the life shock $f(\varepsilon)$ :

$$
\int_{\varepsilon}\left(\left(a_{k}\right)^{\alpha}\left(e_{k}\right)^{\beta}+\varepsilon_{k}\right)^{-\xi} f(\varepsilon) d \varepsilon=\frac{\gamma}{\left(a_{k}\right)^{\alpha} \beta}\left(e_{k}\right)^{\gamma-\beta} .
$$

We assume individual's intrinsic ability and random life shock are normally distributed over the aggregate population; that is, $a_{k} \sim N\left(\mu_{a}, \sigma_{a}^{2}\right), \varepsilon_{k} \sim N\left(\mu_{\varepsilon}, \sigma_{\varepsilon}^{2}\right)$. We assign the following parameters: total population $=5000, \mu_{a}=100, \sigma_{a}^{2}=100, \mu_{\varepsilon}=0, \sigma_{\varepsilon}^{2}=100, \alpha=1.1$, $\beta=0.9, \zeta=0.8$, and $\gamma=1.2 .{ }^{9}$ Given the distribution of ability and the random life shock, we compute an individual's optimal work effort based on Equation 11 or 12, which then can be used to generate the income distribution for the whole population. For any arbitrarily chosen income level $I^{*}$, individual $k$ is categorized as relatively rich if $I_{k}>I^{*}$ and relatively poor if $I_{k}<I^{*}$. Additionally, we denote high ability as being greater than the population average $\left(a_{k}>a_{\text {avg }}\right)$ and low ability as below average. Similarly, individual $k$ with $e_{k}>e_{\text {avg }}$ is treated as working hard. Given these specifications, we obtain the probabilities of individual $k$ being born with a high ability $\left(a_{k}>a_{\text {avg }}\right)$, working hard in the market $\left(e_{k}>e_{\text {avg }}\right)$, and being shocked by good luck $\left(\varepsilon_{k}>0\right)$, respectively. Simulation results under the realized life shock based on Equation 10 are similar to those under the expected life shock based on Equation 12. To save space, we present the results with the expected life shock in Figure 3.

Figure 3 demonstrates that for any threshold income $I^{*}$, relatively rich individuals tend to work hard in the market even though they are more likely to be born with a high ability and being the recipients of a positive life shock than the relatively poor. When we plot an individual's ability, effort level, and the related life shock with income, the results demonstrate that on average, income is positively correlated with ability $a_{k}$, effort $e_{k}$, and life shock $\varepsilon_{k}{ }^{10}$

\subsection{Implications}

Based on our simulation results, we argue that perception bias increases with individual income; specifically, $d a_{j}^{*} / d I_{i}>0, d e_{j}^{*} / d I_{i}<0$, and $d \varepsilon_{j}^{*} / d I_{i}>0$. Recall that the effects of perception bias regarding the relationship between income and charitable giving are captured by $-1 /\left(f^{\prime \prime}+4 h^{\prime \prime}+g_{c_{i} c_{i}}\right) *\left(g_{c_{i} a_{j}^{*}} * d a_{j}^{*} / d I_{i}+g_{c_{i} e_{j}^{*}} * d e_{j}^{*} / d I_{i}+g_{c_{i} \varepsilon_{j}^{*}} * d \varepsilon_{j}^{*} / d I_{i}\right)$. Given our model's specifications, $-1 /\left(f^{\prime \prime}+4 h^{\prime \prime}+g_{c_{i} c_{i}}\right)>0$, and our simulation results imply $g_{c_{i} e_{j}^{*}} * d e_{j}^{*} / d I_{i}<0$ and $g_{c_{i} a_{j}^{*}} * d a_{j}^{*} / d I_{i}>0$. Depending on the type of charity,

9 Simulation results are robust to a wide range of parameters. Matlab code is available upon request.

10 We do not present related figures here in order to save space. Results are available upon request. 
we have $g_{c_{i} a_{j}^{*}} * d a_{j}^{*} / d I_{i}<0$ for charities designed to help low-ability recipients and $g_{c_{i} a_{j}^{*}} * d a_{j}^{*} / d I_{i}>0$ for charities designed to help high-ability recipients. We summarize these results in the following proposition.

Proposition 2. Perception bias increases with individual income, and perception bias of the recipient's situation does not necessarily decrease the donor's charitable giving. Specifically, perception bias of the recipient's working effort decreases the donor's charitable giving $\left(g_{c_{i} e_{j}^{*}} * d e_{j}^{*} / d I_{i}<0\right)$; perception bias of the recipient's life shock decreases the donor's charitable giving $\left(g_{c_{i} \varepsilon_{j}^{*}} * d \varepsilon_{j}^{*} / d I_{i}<0\right)$; and perception bias of the recipient's ability decreases the donor's giving to charities designed to help low-ability recipients $\left(g_{c_{i} a_{j}^{*}} * d a_{j}^{*} / d I_{i}<0\right)$, but increases the donor's giving to charities designed to help highability recipients $\left(g_{c_{i} a_{j}^{*}} * d a_{j}^{*} / d I_{i}>0\right)$.

Proposition 2 implies that adding perception bias does not necessarily decrease an individual's charitable giving. The net effect depends on the type of charity and the donor's income level.

With regard to charity recipients, Figure 4 shows that giving to education (which generally represents giving to high-ability recipients) in the United States has been rising ever since the 1980s, as has the charity given to human services (which generally represents giving to low-ability recipients). ${ }^{11}$ The solid curve in Figure 4 indicates that giving to education as a share of total charitable giving increased from $10 \%$ in the 1980 s to over $15 \%$ in 2014 , which represents a good opportunity for colleges and universities. The share of giving to human services fluctuates substantially decreasing from $15 \%$ in the 1970 s to less than $5 \%$ in the 1980 s and then reaching 12\% in 2014. A recent study surveyed 20,000 high-net-worth donors among the wealthiest neighbourhoods in the United States finding that wealthy households were most likely to give to education, and among all charitable sectors, education received the largest share of dollars (27\%), while basic needs received only $3.3 \%$ in $2013 .{ }^{12}$

Given these observations and based on our findings, we propose a set of strategic suggestions for charitable organizations. Fundraising professionals shall focus their efforts and resources on correcting the donors' perception bias when raising money charities with low-ability recipients, especially for rich donors. This can be done by providing information to show that recipients are actually born with low ability and working hard but shocked by bad luck. When raising money for charities with high-ability recipients, however, charity organizations should correct the donor's perception bias of the recipient's effort and life shock but may increase the bias regarding the recipient's ability. It is of course difficult to ascertain the donor's precise perception of recipients, but it is not impossible to provide related information in such a way to shed light on the recipient's situation and let the donors select the recipient they would like to support.

11 Data source: Giving USA 2015.

12 The 2014 U.S. Trust Study of High Net Worth Philanthropy-Issues Driving Charitable Activities among Wealthy Households. Only households with incomes greater than $\$ 200,000$ and/or net worth more than $\$ 1,000,000$-excluding the monetary value of their home-were included in this analysis. http://www.ustrust.com/ust/pages/philanthropy.aspx 
Recall that our theoretical analysis in Section 2 indicates that donors' attitude towards inequality counteracts the effects of perception bias. Therefore, fundraising professionals shall allocate additional effort to understand the level of the donor's inequality aversion. Combined with Proposition 2, we further suggest that fundraising professionals shall spend relatively more effort on correcting the donors' perception bias, especially for those donors who do not care inequality that much, when raising money for charities with low-ability recipients.

\section{Conclusion}

Individual giving is critical to charitable organizations, but the percentage of income donated to charity has been relatively stable despite per capita income increasing considerably over time. This paper explores the relationship between income and charitable giving from the perspective of perception bias. We propose a model that incorporates impure altruism, inequality aversion, and perception bias, where the donor's warm glow from charitable giving depends on his perception of the recipients' situation.

We showed that perception bias increases with individual income, and donors' perception bias does not necessarily decrease their charitable giving. Specifically, perception bias of the recipients' effort and life shock decreases donors' charitable giving. Perception bias of the recipients' ability decreases donors' giving to charities intended to help low-ability recipients but increases their giving to charities intended to help highability recipients. Fundraising professionals should use this information when approaching potential donors by focussing their efforts on correcting the donors' perception bias of the recipients' ability, effort, and life shock when raising money charities for lowability recipients. However, when raising money for high-ability recipients, fundraising professionals should correct donors' perception bias of the recipients' effort and life shock but increase their perception bias of the recipients' ability. Additionally, our general setting allows us to disentangle the effects of donors' attitude towards inequality, which has been shown to counteract the effects of perception bias. Therefore, understanding the donor's attitude towards inequality is critical for fundraising professionals to allocate their effort efficiently: when correcting the donors' perception bias, they shall focus their efforts especially on those who do not care inequality that much. More specifically, fundraising professionals shall allocate relatively more effort on correcting the donors' perception bias, especially for those donors who do not care inequality that much, when raising money for charities with low-ability recipients.

In reality, of course, various factors affect individual giving. This paper should be treated as a step towards a better understanding of the role of perception bias in charitable giving. Further empirical research could involve a lab experiment to explore factors that affect individuals' perception bias and their effects on charitable giving for various types of donors and recipients. Another type of perception bias, the perception bias of income distribution, is not considered in this paper. Future research may extend our analysis by incorporating this additional perception bias given its importance in political economy and public economic models. 
Figures

Figure 1 | U.S. Charitable Giving by Source

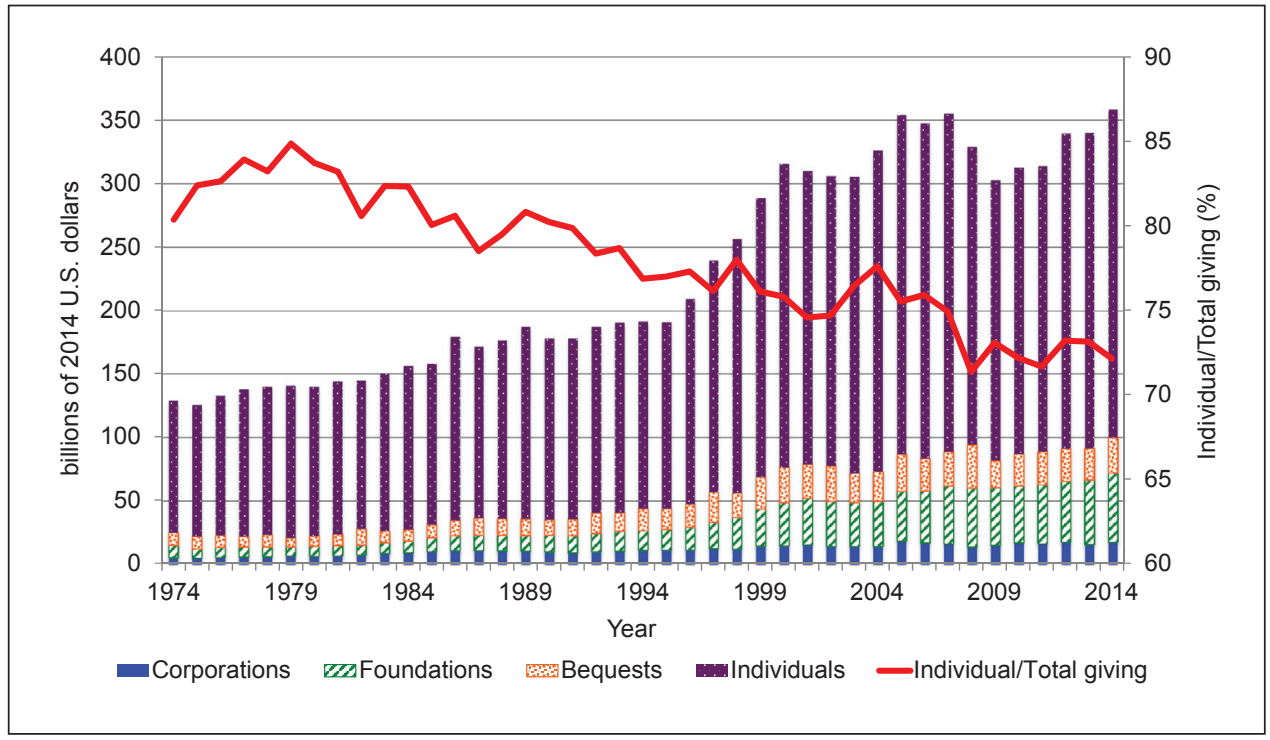

Source: Giving USA, 2015

Figure 2 | U.S. Individual Giving and Disposable Personal Income (DPI)

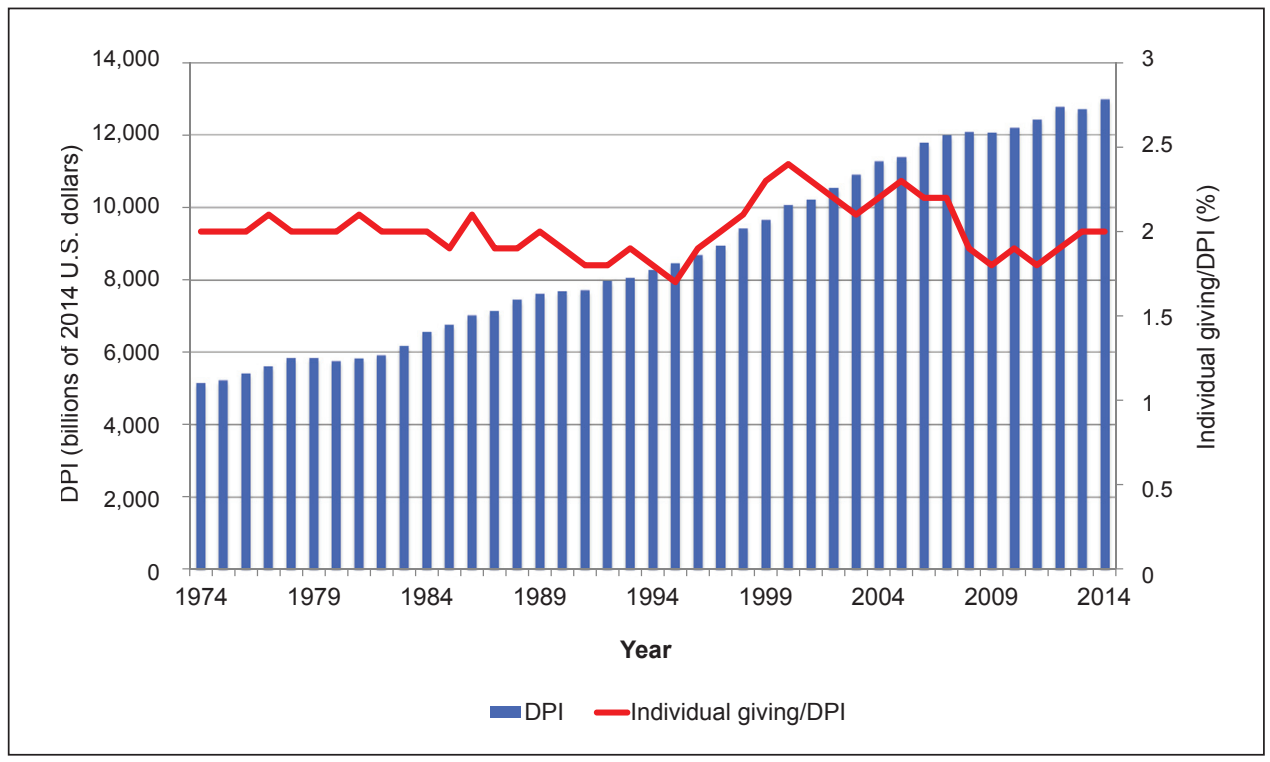

Source: Giving USA, 2015 
Figure 3 | Simulation Results with Expected Life Shock

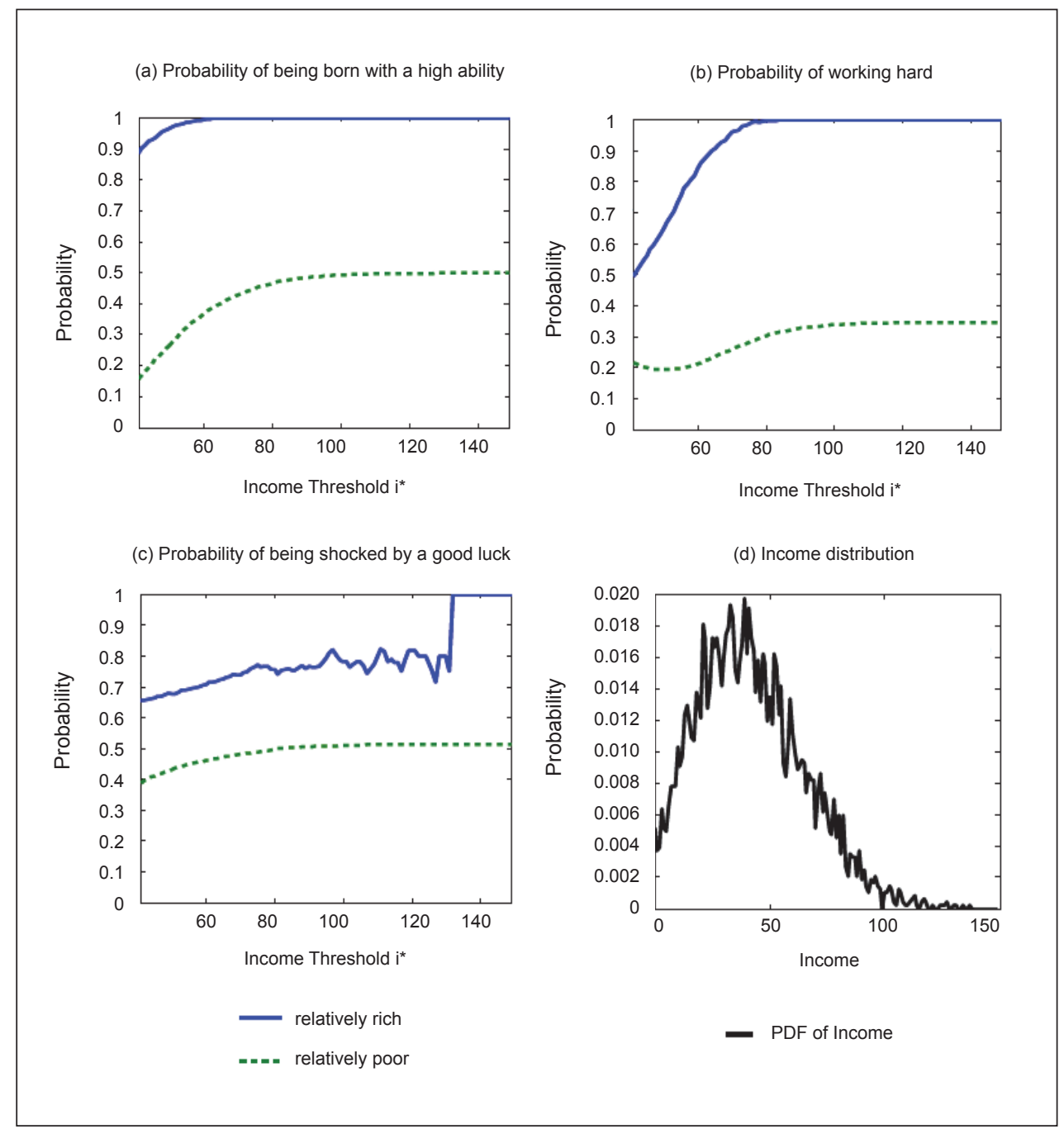

Source: Authors' simulation with normally distributed life shock. 


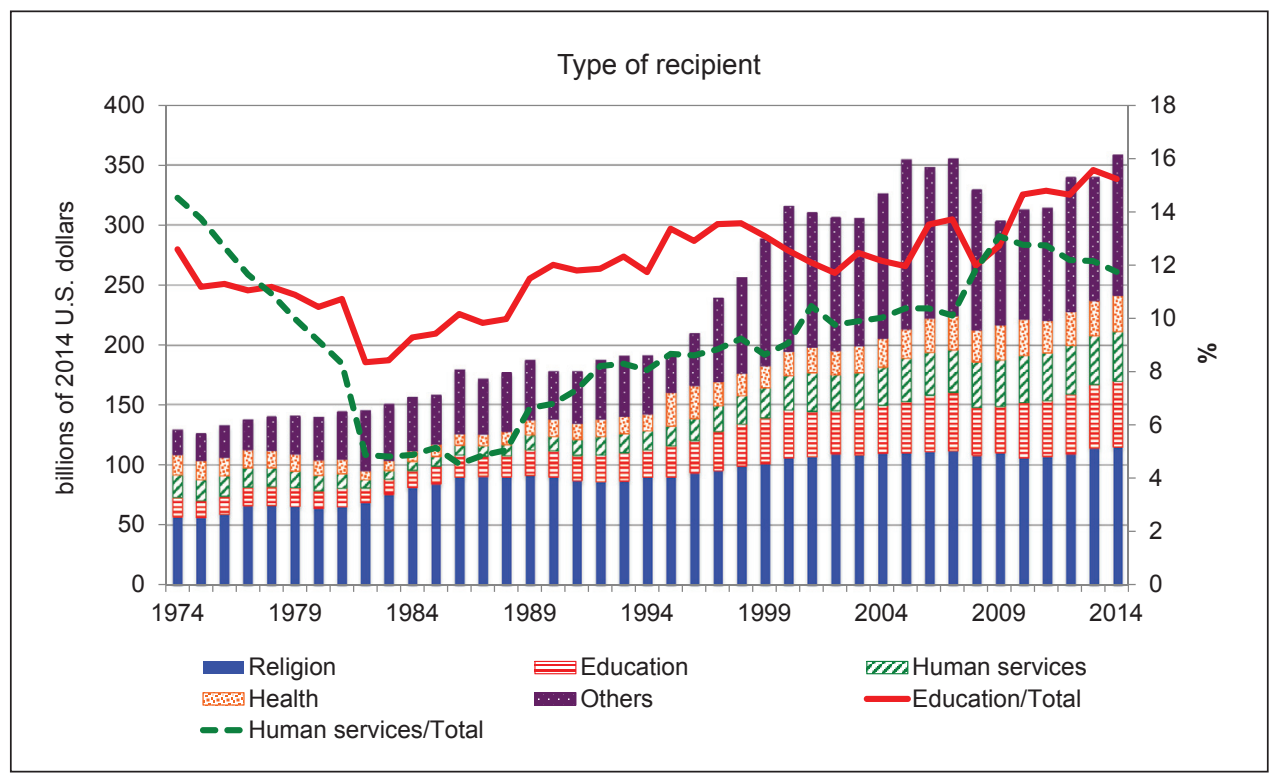

Source: Giving USA, 2015

\section{Appendix}

\section{The Original M-T Model}

Mayo and Tinsley (2009) assume that household A has the following utility function

$$
U=U\left(X_{A}, Y_{B}, \omega\right)
$$

Where $X_{A}$ represents the consumption of household A, $Y_{B}$ denotes the total supply of charity given to household $\mathrm{B}$ (who is less well off than $\mathrm{A}$ ), and $\omega$ is the warm glow A experiences by giving to $\mathrm{B}$.

They further specify a household's earned income as determined by the level of effort $e$ and a random shock $\varepsilon$ as below

$$
M_{i}=f\left(e_{i}\right)+\varepsilon, \text { where } i=A, B
$$

with $\frac{\partial}{\partial} \quad$ and $\varepsilon \sim N(0, \sigma)$.

Besides the earned income, household $\mathrm{B}$ receives charity $C$ and gets a total income

$$
M_{B}^{\prime}, M_{B}+C \text { with } C=C\left(\omega, p, M_{A}\right)
$$

where $p$ represents the price of charitable giving. The key of Mayo and Tinsley (2009) is that they incorporate perception bias in the warm glow $\omega$ by specifying 


$$
\omega=g\left(e_{B^{*}}, \varepsilon_{B^{*}}\right) \text {, where } \frac{\partial g}{\partial e_{B^{*}}}>0 ; ;^{\frac{\partial^{2} g}{\partial e_{B^{*}}{ }^{2}}>0 ;} \text { and } \frac{\partial g}{\partial \varepsilon_{B^{*}}} \leq 0 \text {. }
$$

Here, $e_{B}$ and $\varepsilon_{B}$ denote A's perception of B's effort and B's luck.

Based on the above model set up, Mayo and Tinsley (2009) then use a simple and illustrative figure to demonstrate the effects of perception bias on charity by assuming the rich household A has good luck $\left(\varepsilon_{A}>0\right)$ and the poor household B has bad luck $\left(\varepsilon_{B}>0\right)$. The total distortion in A's perception of B's effort comes from A's discounting of B's bad luck (the fundamental attribution error) and A's discounting of its own good luck (selfserving attribution bias).

To illustrate how the individual effects aggregate over the population, Mayo and Tinsley (2009) adopt the following simulation method. They assume a linear function for the earned income

$$
M_{A}=e_{A},+\varepsilon,
$$

where $e$ follows a uniform distribution ranging from 0 to 100 , and $\varepsilon \sim N(0,15)$. Simulation results show that wealthy households are more likely to be the recipient of good luck, implying that "the wealthy households will, on average, be exposed to the fundamental attribution error, ... will be prone to a diminution in warm glow and, hence, charitable giving".

\section{References}

Andreoni, J. (1989). Giving with Impure Altruism: Applications to Charity and Ricardian Equivalence. The Journal of Political Economy, 97(6), 1447-1458, https://doi. org/10.1086/261662

Andreoni, J. (1990). Impure Altruism and Donations to Public Goods: A Theory of Warm-glow Giving. The Economic Journal, 100(401), 464-477, https://doi.org/10.2307/2234133

Andreoni, J. (1995). Cooperation in Public-Goods Experiments: Kindness or Confusion. American Economic Review, 85(4), 891-904.

Andreoni, J. (2006). Philanthropy, in Kolm, S.C. and J.M. Ythier, ed., Volume 2 of Handbook on the Economics of Giving, Reciprocity and Altruism. Elsevier, 1201-1269.

Andreoni, J., Vesterlund, L. (2001). Which Is the Fair Sex? Gender Differences in Altruism. Quarterly Journal of Economics, 116(1), 293-312, https://doi. org/10.1162/003355301556419

Auten, G. E., Sieg, H., Clotfelter, C. T. (2002). Charitable Giving, Income, and Taxes: An Analysis of Panel Data. American Economic Review, 92(1), 371-382, https://doi. org/10.1257/000282802760015793

Bashir, N., Dayson, C., Eadson, W., Wells, P. (2013). A Warm Glow in All Parts? Building Local Cause-Affinity as a Strategy for Promoting Charitable Giving. People, Place \& Policy Online, 7(3), 139-152, https://doi.org/10.3351/ppp.0007.0003.0003

Becker, G. S. (1974). A Theory of Social Interactions. Journal of Political Economy, 82(6), $1063-$ 1093, https://doi.org/10.1086/260265 
Bekkers, R., Wiepking, P. (2007). Generosity and Philanthropy: A Literature Review.

SSRN Working Paper No. 1015507, https://doi.org/10.2139/ssrn.1015507

Bekkers, R. H. (2004). Giving and Volunteering in the Netherlands: Sociological and Psychological Perspectives. Utrecht University.

Bennett, R. (2012). Why Urban Poor Donate: A Study of Low-Income Charitable Giving in London. Nonprofit and Voluntary Sector Quarterly, 41(5), 870-891, https://doi. org/10.1177/0899764011419518

Bolton, G. E., Ockenfels, A. (2000). ERC: A Theory of Equity, Reciprocity, and Competition. American Economic Review, 26(1), 51-74.

Buckley, E., Croson, R. (2006). Income and Wealth Heterogeneity in the Voluntary Provision of Linear Public Goods. Journal of Public Economics, 90(4), 935-955, https://doi. org/10.1016/j.jpubeco.2005.06.002

Carroll, J., McCarthy, S., Newman, C. (2005). An Econometric Analysis of Charitable Donations in the Republic of Ireland. Economic and Social Review, 36(3), 229-249.

Cruces, G., Perez-Truglia, R., Tetaz, M. (2013). Biased Perceptions of Income Distribution and Preferences for Redistribution: Evidence from a Survey Experiment. Journal of Public Economics, 98(3), 100-112, https://doi.org/10.1016/j.jpubeco.2012.10.009

Donoghue, F., Ruddle, H. (2000). Warm Glow in a Cool Climate? Philanthropy in Ireland. Paper presented to the International Society for Third Sector Research Fourth Biennial Conference Dublin.

Erkal, N., Gangadharan, L., Nikiforakis, N. (2011). Relative Earnings and Giving in a Real-Effort Experiment. The American Economic Review, 101(7), 3330-3348, https://doi.org/10.1257/ aer.101.7.3330

Fehr, E., Schmidt, K. M. (1999). A Theory of Fairness, Competition, and Cooperation. The Quarterly Journal of Economics, 114(3), 817-868, https://doi. org/10.1162/003355399556151

James, R. N., Sharpe, D. L. (2007). The Nature and Causes of the U-Shaped Charitable Giving Profile. Nonprofit and Voluntary Sector Quarterly, 36(2), 218-238, https://doi. org/10.1177/0899764006295993

Mayo, J. W., Tinsley, C. H. (2009). Warm Glow and Charitable Giving: Why the Wealthy Do Not Give More to Charity? Journal of Economic Psychology, 30(3), 490-499, https:// doi.org/10.1016/j.joep.2008.06.001

Miller, D. T., Ross, M. (1975). Self-Serving Biases in the Attribution of Causality: Fact or Fiction? Psychological Bulletin, 82(2), 213-225, https://doi.org/10.1037/h0076486

Mullen, B., Riordan, C. A. (1988). Self-Serving Attributions for Performance in Naturalistic Settings: A Meta-Analytic Review. Journal of Applied Social Psychology, 18(1), 3-22, https://doi.org/10.1111/j.1559-1816.1988.tb00001.x

Ross, L. (1977). The Intuitive Psychologist and His Shortcomings: Distortions in the Attribution Process. Advances in Experimental Social Psychology, 10, 173-220, https://doi.org/10.1016/s0065-2601(08)60357-3

Tonin, M., Vlassopoulos, M. (2014). An Experimental Investigation of Intrinsic Motivations for Giving. Theory and Decision, 76(1), 47-67, https://doi.org/10.1007/s11238-013-9360-9

Vesterlund, L. (2006). Why Do People Give, in Powell, W. and R.S. Steinberg, ed., The Nonprofit Sector: A Research Handbook 2. New Haven, CT: Yale University, pp. 168-190.

Wiepking, P. (2007). The Philanthropic Poor: In Search of Explanations for the Relative Generosity of Lower Income Households. Voluntas: International Journal of Voluntary and Nonprofit Organizations, 18(4), 339-358, https://doi.org/10.1007/s11266-007-9049-1 